NOAA

National Marine

Fisheries Service
Fishery Bulletin

$\curvearrowright$ established 1881 \%
Spencer F. Baird

First U.S. Commissione of Fisheries and founder of Fishery Bulletin
Abstract-Dolphinfish (Coryphaena hippurus), large pelagic predators and important fishery targets, frequently associate with floating debris or manmade fish aggregating devices (FADs). We tagged 8 dolphinfish with pressure-sensitive ultrasonic transmitters and actively tracked individuals continuously for up to $40 \mathrm{~h}$ to elucidate the vertical movement patterns and differences between FADassociated (FAD-A) and FAD-unassociated (FAD-U) fish. Four additional fish were equipped with acoustic transmitters and passively monitored for several days with receivers attached to FADs. When not associated with FADs, dolphinfish used the upper $75-100 \mathrm{~m}$ of the water column during the day and made descents up to $160 \mathrm{~m}$ during the night. In contrast, FAD-A fish generally stayed within the upper $10 \mathrm{~m}$ of the water column and tended to make deeper excursions during the day rather than at night. Water temperature data from expendable bathythermographs deployed during active tracking showed that fish only descended to depths where temperatures were $\leq 3^{\circ} \mathrm{C}$ cooler than the uniform-temperature surface layer. The use of vertical behavior to determine whether a dolphinfish is associated or not with a floating object opens the possibility for new, large-scale research aimed at investigating the role of floating objects in the ecosystem inhabited by this species and at assessing the impacts of FADs on its ecology.

Manuscript submitted 2 June 2015. Manuscript accepted: 14 July 2016. Fish. Bull.: 426-434 (2016).

Online publication date: 8 August 2016. doi: 10.7755/FB.114.4.5

The views and opinions expressed or implied in this article are those of the author (or authors) and do not necessarily reflect the position of the National Marine Fisheries Service, NOAA.

\title{
Swimming depth of dolphinfish (Coryphaena hippurus) associated and unassociated with fish aggregating devices
}

\author{
Nicholas M. Whitney (contact author) ${ }^{1}$ \\ Marc Taquet $^{2}$ \\ Richard W. Brill ${ }^{3}$ \\ Gail D. Schwieterman' \\ Laurent Dagorn4 \\ Kim N. Holland ${ }^{5}$ \\ Charlotte Girard ${ }^{4}$ \\ Email address for contact author: nwhitney@mote.org \\ ${ }^{1}$ Behavioral Ecology and Physiology Program \\ Mote Marine Laboratory \\ 1600 Ken Thompson Parkway \\ Sarasota, Florida 34236 \\ 2 Unités Mixtes de Recherché (UMR) \\ Ecosystèmes Insulaires Océaniens (EIO) \\ Institut de Recherche pour le Développement \\ BP 529 \\ 98713 Papeete, Tahiti, Polynésie française \\ 3 Pacific Islands Fisheries Science Center \\ ${ }^{4}$ Unités Mixtes de Recherché (UMR) Marine \\ Biodiversity, Exploitation, and \\ Conservation (MARBEC) \\ Institut de Recherche pour le Développement \\ Avenue Jean Monnet CS 30171 \\ 34203 Sète Cedex, France \\ ${ }^{5}$ Hawaii Institute of Marine Biology \\ University of Hawaii at Manoa \\ P.O. Box 1346 \\ Kaneohe, Hawaii 96744
}

National Marine Fisheries Service, NOAA

2570 Dole Street

Honolulu, Hawaii 96822-2396
Dolphinfish (Coryphaena hippurus) are large pelagic fish that are common globally in tropical and warm temperate seas (Palko et al., 1982). They have diverse diets composed of floating debris-associated organisms, such as portunids (crabs) and epipelagic cephalopods (Olson and GalvánMagaña, 2002; Rudershausen et al., 2010), as well as neritic and demersal fish (Tripp-Valdez et al., 2010). The fast growth rate (Schwenke and Buckle, 2008; Furukawa et al., 2012), early sexual maturity (less than one year; Trippel, 1995; Furukawa et al., 2012), and high food value (Beardsley, 1967; Rodríguez-Ferrer et al., 2004) of this species makes it an increasingly important target of commercial, sport, and artisanal fisheries (RodríguezFerrer et al., 2004). The tendency of dolphinfish to aggregate around floating objects and flora, such as sargassum (Oxenford, 1999; Rooker et al.,
2006; Casazza and Ross, 2008; Farrell et al., 2014; Merten et al., 2014a), logs (Baughman, 1941), and manmade fish aggregating devices (FADs; Rose and Hassler, 1974; Massutí et al., 1998, Oxenford and Hunte, 1999; Dempster, 2004; Dagorn et al., 2007; Taquet et al., 2007), facilitates their exploitation by both commercial and recreational fisheries throughout the world.

Recent estimates put annual catch of dolphinfish at more than 102,986 metric tons (t) (FAO, 2013), which excludes unreported bycatch (common in longline tuna fisheries) and underreported artisanal landings. A recent study estimated that $5382 \mathrm{t}$ of illegal or unreported dolphinfish were imported from Ecuador to the United States in 2011 alone (Pramod et al., 2014). The high exploitation rate and commercial importance of this species justify a better foundational knowledge of the life history and behavioral 


\section{Table 1}

Characteristics of the tracking or monitoring of dolphinfish, including which method was used: active (boat-based) or passive (receiver attached to a fish aggregating device [FAD]). Behavior categories are day (D) or night (N) and either FAD-unassociated (U) or FAD-associated (A). FAD types (drifting or anchored) are listed only for animals that were actually associated with a FAD for a part of the time they were tracked.

\begin{tabular}{|c|c|c|c|c|c|c|c|}
\hline Method & Fish & $\begin{array}{l}\text { Fork length } \\
(\mathrm{cm})\end{array}$ & $\begin{array}{l}\text { Tracking } \\
\text { start date }\end{array}$ & $\begin{array}{l}\text { Duration of } \\
\text { tracking }(\mathrm{h})\end{array}$ & $\begin{array}{l}\text { Behavior } \\
\text { category }\end{array}$ & FAD type & Location \\
\hline \multirow[t]{7}{*}{ Active } & 1 & 125 & 4-Mar-86 & 40.1 & DU/NU & \multirow{7}{*}{$\begin{array}{l}\text { drifting } \\
\text { anchored }\end{array}$} & Hawaii \\
\hline & 2 & 108 & 3-Feb-87 & 6.0 & DU & & Hawaii \\
\hline & 3 & 103 & 7-Mar-87 & 22.5 & DU/NU & & Hawaii \\
\hline & 4 & 104 & 24-Mar-87 & 27.2 & DU/NA & & Hawaii \\
\hline & 6 & 124 & 6-Aug-03 & 8.0 & DU & & Réunion Is. \\
\hline & 7 & 58 & 12-Apr-05 & 4.3 & $\mathrm{DU}^{1}$ & & Seychelles \\
\hline & 8 & 69 & 21-Apr-05 & 7.5 & $\mathrm{DU}^{1}$ & & Seychelles \\
\hline \multirow[t]{4}{*}{ Passive } & 9 & 110 & 13-Dec-01 & 38.4 & DA/NA & drifting & S. Indian \\
\hline & 10 & 77 & 12-Oct-03 & 81.6 & DA/NA & drifting & S. Indian \\
\hline & 11 & 86 & 8-Feb-04 & 87.8 & DA/NA & drifting & Seychelles \\
\hline & 12 & 102 & 16-Oct-04 & 84.5 & DA/NA & drifting & Seychelles \\
\hline
\end{tabular}

${ }^{1}$ Fish tracked in shallow areas (depths of 50-60 m) were not included in statistical analyses.

patterns of dolphinfish in order to ensure development of appropriate measures for fishery management and resource conservation.

Previous studies of the movements of dolphinfish have focused either on broadscale migrations or on movements in highly specific contexts. For example, Merten et al. (2014a) used mark-recapture data to describe broadscale migrations along the East Coast of the United States, from the Florida Keys to Long Island, New York. Merten et al. (2014b) used plastic dart tags and pop-off satellite tags to determine regional patterns of horizontal movement, and Norton (1999) described a global poleward shift of dolphinfish that corresponded with an increase in ocean temperatures.

Individual dolphinfish have been shown to home to a specific moored FAD (Girard et al., 2007) and to remain associated with an anchored FAD for a mean duration of 3.98 days (Dagorn et al., 2007) and with drifting FADs for a mean duration of 6.25 days (Taquet et al., 2007). Dolphinfish in the western Atlantic generally maintain swimming depths in the uniform-temperature surface layer and descend beyond the surface layer (0$10 \mathrm{~m}$ ) longer at night than during the day, possibly to forage (Merten et al., 2014c). FAD-U fish in the northern East China Sea often remain above the thermocline (Furukawa et al., 2011), although Merten et al. (2014c) found that the thermocline was not a barrier to vertical movements for dolphinfish in the Atlantic. In general, dolphinfish have the shallowest vertical distribution of other sympatric, mid-trophic level predators, such as the striped marlin (Kajikia audax; Brill et al., 1993) and sailfish (Istiophorus platypteru; Hoolihan, 2005).

To date, the movement patterns between FAD-A and FAD-U dolphinfish have not been compared. We ana- lyzed the vertical swimming behavior of both FAD-A and FAD-U dolphinfish, tracked by using active and passive telemetry, with particular regard to diurnal patterns. Understanding the vertical movement patterns of this commercially important species is increasingly essential for sustainable fisheries management, especially in the face of climate change. The use of a comprehensive ethology will enable managers to predict changes in distribution of dolphinfish as seawaters warm and to implement bycatch reduction regulations, such as a mandate that would limit the depths at which gear can be set to depths outside the range preferred by dolphinfish.

\section{Materials and methods}

\section{Study sites}

A total of 12 dolphinfish were tagged and released at locations 1) in the central Pacific (near the main Hawaiian Islands, n=4) in 1986 and 1987, 2) in the southwestern Indian Ocean (near Réunion Island; $n=4$ ) in 2005, and 3) in the Western Indian Ocean (near Seychelles, $n=4$ ) in 2003 (Table 1). In the central Pacific, active tracking of 4 fish was conducted off the northeast (windward) coast of Oahu near an array of FADs that consisted of surface buoys anchored at depths from 670 to $3660 \mathrm{~m}$. The tracks of 4 more fish were recorded with active telemetry around FADs made of about 10 surface buoys, a metal cable, and strap bands located on the cable at a depth of $\sim 20 \mathrm{~m}$, anchored with concrete blocks on the Seychelles Plateau in relatively shallow $(50-60 \mathrm{~m})$ water or around drifting FADs of similar construction. In the open sea off Réunion Island, 2 fish were passively monitored in 
depths of 2000-5000 m, one fish in 2001 and another in 2003, by using drifting FADs, made of bamboo rafts with trailing netting panels, that were deployed specifically to study pelagic fish aggregations (Taquet, 2004). Off the Seychelles Plateau in 2004, 2 more fish were passively monitored near FADs made of surface buoys anchored at depths of 500-1500 m (Girard et al., 2007). Fish from all locations were caught by trolling and pole techniques and were brought aboard the vessel for tagging.

\section{Active telemetry}

A detailed account of the tracking methods employed in Hawaii are described in Holland et al. (1985), and those used off Réunion Island and in the Seychelles are detailed in Girard et al. (2007). In Hawaii, pressure-sensitive V16 ultrasonic transmitters $(16.0 \mathrm{~mm}$ in diameter, $27.7 \mathrm{~g}$ in air and $11.7 \mathrm{~g}$ in seawater; Vemco Inc. ${ }^{1}$, Bedford, Nova Scotia, Canada) were attached externally to a fish by passing 2 nylon cable ties through the dorsal or ventral pterygiophores and trunk musculature adjacent to the second dorsal fin (we switched to the latter procedure after one fish was observed swimming at the surface with its dorsal tag carried above the surface of the water). The transmitters were equipped with pressure sensors that modulated the rate of pulses transmitted in response to changes in water pressure (depth). Therefore, vertical movements of the fish were determined by measuring the time between signal pulses (e.g., Holland et al., 1990b). Individuals were held out of the water for approximately $1 \mathrm{~min}$ during the tagging procedure. For tracking, we used a $12 \mathrm{~V}$ DC amplifier and receivers (CR40, Vemco Inc.) and a directional hydrophone (Vemco Inc.), which was mounted to a pole extending about 1.5 $\mathrm{m}$ below the surface. Attempts were made to keep the tracking vessel $200 \mathrm{~m}$ away from the tagged individual to maintain maximum signal amplitude and not disturb natural behavior.

The fish actively tracked off Réunion Island were caught at FADs and held in a container of flowing seawater, and the fish caught in the Seychelles were placed in a padded cradle for a few minutes and provided with flow of water to oxygenate their gills. Fish tracked in the Seychelles and off Réunion Island were moved distances of 70-1720 $\mathrm{m}$ from the FAD during tagging, as part of a study on dolphinfish homing abilities around FADs (Girard et al., 2007). For fish tracked in these 2 areas, $\mathrm{V} 16 \mathrm{P}-4 \mathrm{H}$ transmitters $(16.0 \mathrm{~mm}$ in diameter, 25 $\mathrm{g}$ in air and $11 \mathrm{~g}$ in seawater, with a random delay between 40 and $120 \mathrm{~s}$, depth resolutions from 0.3 to 1.5 $\mathrm{m}$; Vemco Inc.) were attached by means of a hook that passed through the pterygiophores of the anal fin. Four hydrophones were towed below the tracking vessel on a V-fin depressor, and the signal emitted by a tag was processed with a VR28 receiver system (Vemco Inc.) connected to a laptop computer to record the data that were

\footnotetext{
${ }^{1}$ Mention of trade names or commercial companies is for identification purposes only and does not imply endorsement by the National Marine Fisheries Service, NOAA.
}

automatically stored in the receiver. Whenever possible, a distance of at least $100 \mathrm{~m}$ was maintained between the tagged fish and the boat to reduce the effect of the tracking vessel on fish behavior.

During active tracking, data for seawater temperature were acquired through periodic deployments of an expendable bathythermograph system (Lockheed Martin Sippican, Marion, MA.). We defined association with a FAD as a fish remaining within $360-655 \mathrm{~m}$ of a FAD or floating debris for at least $30 \mathrm{~min}$, as determined bf direct observation.

\section{Passive telemetry}

Fish were passively monitored with V13P-1H acoustic transmitters that would transmit on a random delay of $40-120 \mathrm{~s}$ (fish 9, 11, and 12; $13 \mathrm{~mm}$ in diameter, $11 \mathrm{~g}$ in air and $6 \mathrm{~g}$ in seawater; Vemco Inc.). Tags were inserted into the peritoneal cavity through an incision of $1-2 \mathrm{~cm}$ made to the side of the ventral centerline of the fish and $2-3 \mathrm{~cm}$ anterior to the cloaca. The wound was closed by using sterile needles and suture material; the entire procedure was completed in less than 3 min. Fish 10 was equipped with a V16P-4H acoustic transmitter on a delay of $10-30 \mathrm{~s}$ ( $18 \mathrm{~mm}$ in diameter, $36 \mathrm{~g}$ in air and 16 $\mathrm{g}$ in seawater; Vemco Inc.) attached above their anal fin with a hook. To monitor tagged fish around FADs, VR2 receivers (Vemco Inc.) were suspended $5 \mathrm{~m}$ below a buoy that was tied to the FAD. Following Girard et al. (2007), we defined association of passively monitored fish as fish remaining within the detection range of the transmitters on the FAD (distances of 360 and $655 \mathrm{~m}$ for V13P- $4 \mathrm{H}$ and V16P-4H receivers, respectively). After a few days of observation, VR2 receivers were removed from the FADs so that data could be downloaded.

\section{Analyses}

Pooled time-at-depth histograms were constructed with 5- or 10-m bins as described by Holland et al. (1990b). These data subsequently were expressed as a fraction of the total time each fish was followed, and the fractional data bins were averaged across all fish. Fish 7 and 8 were excluded from statistical analyses because their vertical movements were limited by a bottom depth of 50-60 m. A linear mixed-effects model was used to examine the effects of time of day and FAD association on swimming depth. Our model included fixed effects for tagging method, FAD association (associated or unassociated), and time of day (day or night). Additionally, individual fish and location of study site were random effects because it was not our aim to study intraspecific variability or differences that resulted from study site. Our model did not include interaction terms. Models were run with the lmer function in the lme4 package (Bates et al., 2014) in $R$, vers. 2.15.3 (R Core Team, 2013). The candidate model was selected by using the Akaike information criterion, with factor significance determined by pairwise analysis of variance (ANOVA) tests $(\alpha=0.05) . P$ values for pairwise comparisons were computed by using 
Markov chain Monte Carlo methods from the LMERConvenienceFunction package (Tremblay and Ransijn, 2013) in R.

\section{Results}

A total of 8 dolphinfish (mean fork length:; $100.9 \mathrm{~cm}$ [standard deviation (SD) 24.7]) were actively tracked, and 4 fish (mean fork length: $93.8 \mathrm{~cm}$ [SD 15.0]) were monitored with passive acoustic receivers (Table 1). The duration of active tracking of individual fish $(n=8)$ ranged from 4.3 to $40.1 \mathrm{~h}$ (mean duration of tracking: 15.5 h). Actively tracked fish were unassociated with FADs for the majority of the time that they were tracked, with the exception of fish 4 and 5 (Table 1). Passively monitored fish $(n=4)$, and therefore FAD-A fish, were monitored for periods of 38.4-87.8 h (mean duration of tracking: $73.1 \mathrm{~h}$ ).

Four dolphinfish (fish 5, 6, 9, and 11) immediately after release made quick descents that lasted less than $1 \mathrm{~h}$ before they resumed shallower swimming behavior for the remainder of the time that they were tracked. No other response to tagging was observed.

Our analysis revealed that study location and monitoring method did not have a significant effect on swimming depth (variance approached 0 for both effects $(P>0.05)$, and these effects were removed from the model. We did not find significant interaction between time of day (day or night) and FAD association (associated or unassociated) (ANOVA: $P>0.05$ ); therefore, we present values from a reduced model in which depth was dependent on the fixed effects of time of day and FAD association, with individual (fish) as a random effect. We found mean daytime depth of FAD-A fish to be $1.8 \mathrm{~m}$ (SD 8.1), mean nighttime depth of FAD-A fish to be $0.8 \mathrm{~m}$ (SD 1.7), mean daytime depth of FAD-U fish to be $49.5 \mathrm{~m}$ (SD 0.3), and mean nighttime depth of FAD-U fish to be $28.3 \mathrm{~m}$ (SD 2.9).

During the day when not associated with FADs or floating debris, dolphinfish remained within the uniform-temperature surface layer (above the thermocline) and made only limited vertical excursions to depths of 75-100 m. At night, FAD-U fish swam at depths between 30 and $160 \mathrm{~m}$ and ventured into cooler water. However, fish reached depths that were no more than $3^{\circ} \mathrm{C}$ cooler than the uniform-temperature surface layer (Fig. 1). Although FAD-U fish spent an average of $29.4 \%$ of their time in the upper $10 \mathrm{~m}$ of the water column during both day and night, there was
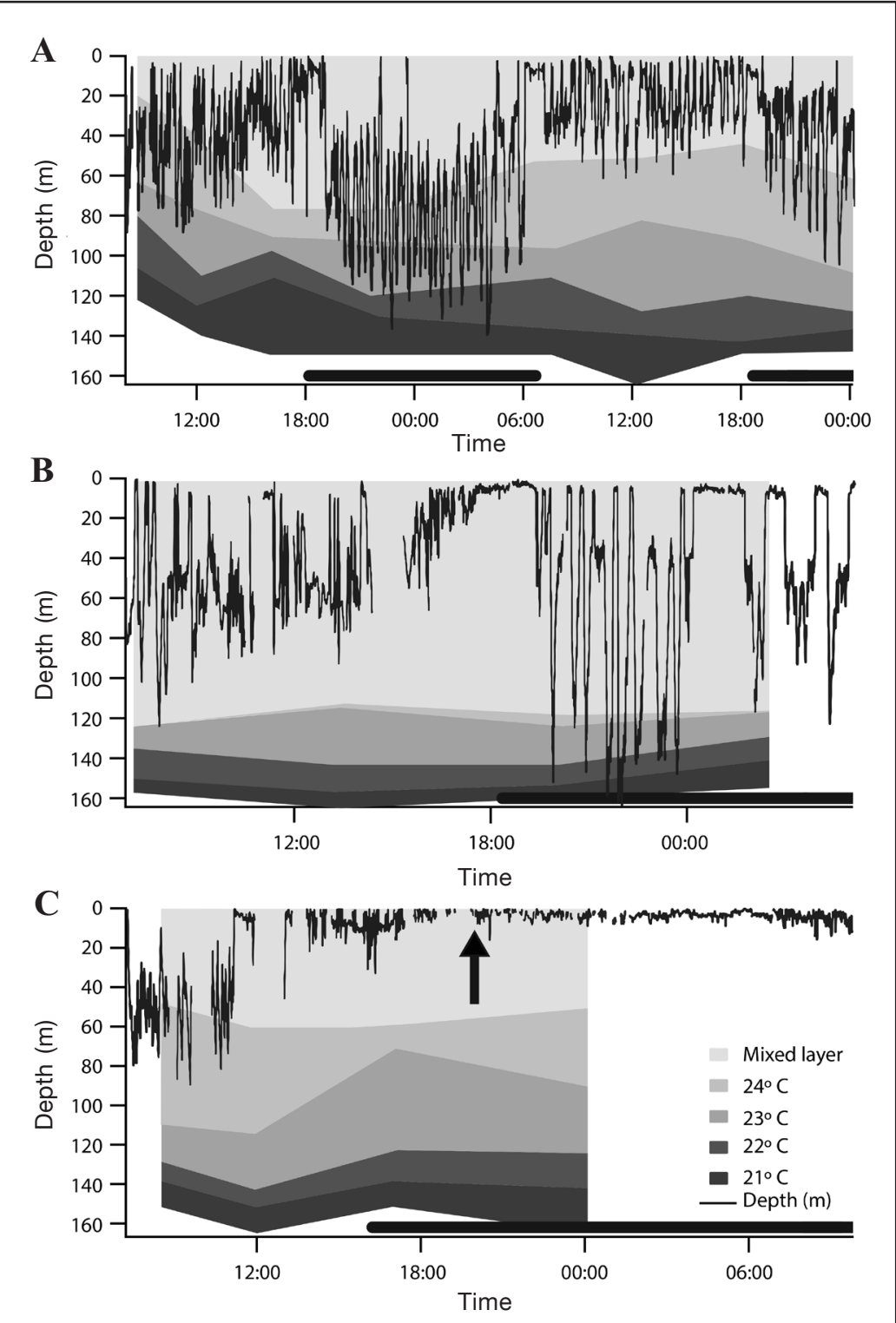

Figure 1

Swimming depth of dolphinfish (Coryphaena hippurus) actively tracked off Oahu, Hawaii, in March 1986 and March 1997: (A) fish 1 during tracking for a period of $40.1 \mathrm{~h}$, (B) fish 3 during tracking for a 22.5-h period, and (C) fish 4 during tracking for a period of $27.2 \mathrm{~h}$. Shades of gray distinguish temperature isotherms. Bold black lines above the $x$-axes indicate nighttime. The arrow in graph $\mathrm{C}$ indicates the time at which fish 4 became associated with drifting debris and numerous other (untagged) dolphinfish. The isotherms are based on temperature recordings from the active acoustic tracking and extend to the last recorded temperature reading. 
A
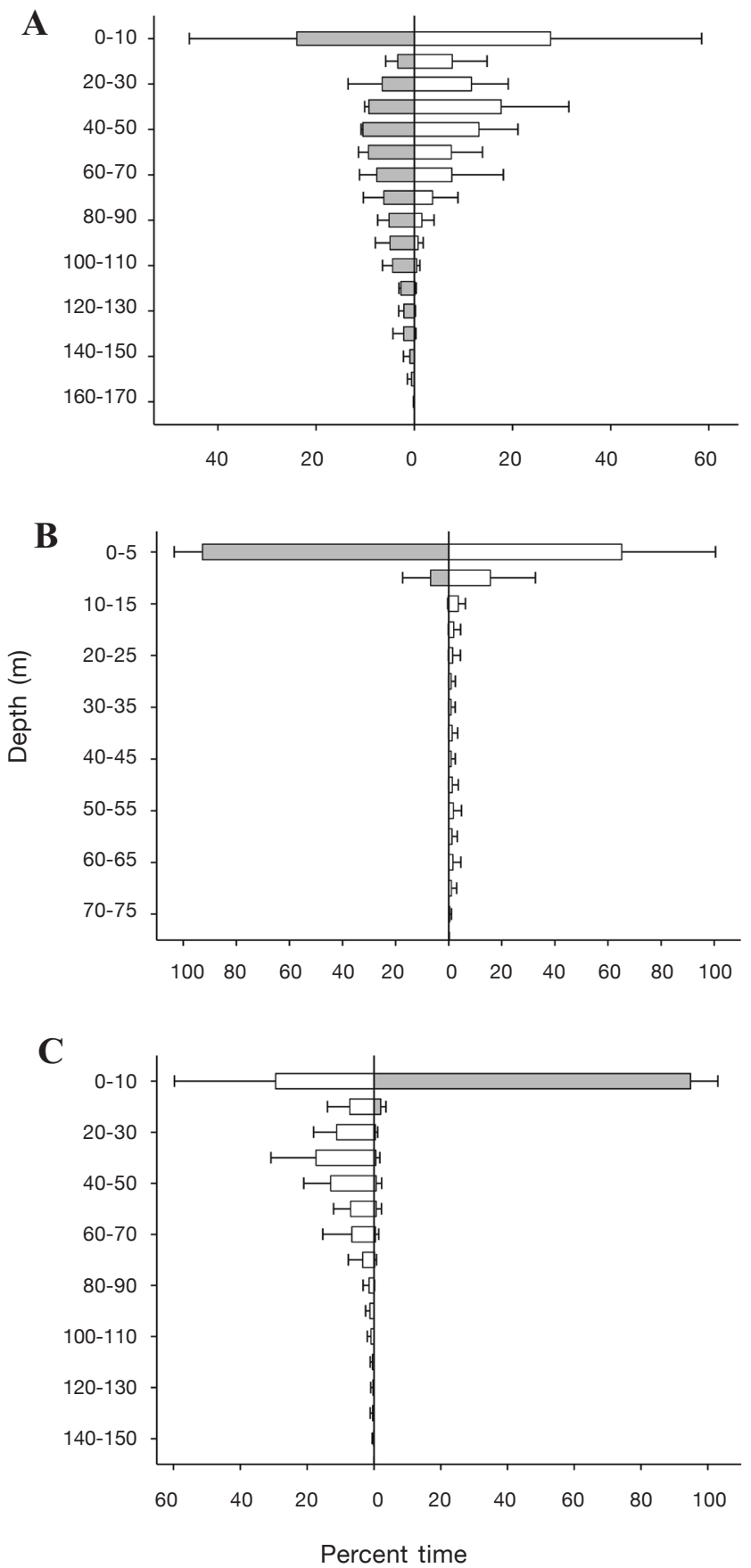

Figure 2

Percent time at depth (A) for all dolphinfish (Coryphaena hippurus) unassociated with a fish aggregating device (FAD) during day (white bars: $n=7$ ) and night (gray bars: $n=2$ ), (B) for FADassociated fish during day (white bars: $n=5$ ) and night (gray bars: $n=5$ ), and (C) for fish unassociated with FADs (white bars: $n=7$ ) and fish associated with FADs (gray bars: $n=6$ ). Sample sizes differ because not all individuals were actively tracked or monitored during full 24-h cycles (see Table 1.). Dolphinfish were actively tracked in Hawaii, Reunion Island, and the Seychelles Plateau between 1986 and 2005 and were passively monitored in the Seychelles Plateau and the Indian Ocean between 2001 and 2004. upper $10 \mathrm{~m}$ of the water column. During the night, fish typically remained within $5 \mathrm{~m}$ of the surface, venturing into depths that were only slightly deeper during the day (Fig 3); this difference was not significant. Only 1 fish (fish 11) exceeded a depth of $30 \mathrm{~m}$ while associated with a FAD (Fig 3). Fish 4 became associated with an abandoned net and other drifting debris while being tracked (Fig. 1). It swam at depths between 25 and $75 \mathrm{~m}$ for the first $4 \mathrm{~h}$ after it was tagged and while it was unassociated with a FAD or debris. After becoming associated with floating debris, this fish remained within the upper $20 \mathrm{~m}$ of the water column for the final $17 \mathrm{~h}$ that it was tracked, and it did not have the deeper nighttime swimming behavior observed in FAD-U fish. These results from active telemetry were confirmed by direct observations of the tagged fish near the surface on several occasions.

By the end of the active tracking of fish 4, approximately 300 dolphinfish, a large school of small yellowfin tuna (Thunnus albacares), and at least 1 marlin (Istiophoridae) were observed to also be associated with debris. No fish were observed to leave a FAD once it became associated with one, and passive monitoring ended when tracked fish were recaptured or the receivers were retrieved. At the end of its passive monitoring, fish 11 showed a rapid descent to more than $200 \mathrm{~m}$ and then exceeded the range of the receiver (not shown in Fig. 3), likely as a result of shedding its tag or possibly mortality.

Actively tracked fish 1 and 3, which were unassociated with floating objects during crepuscular periods, interrupted their vertical movement patterns and remained within the upper $10 \mathrm{~m}$ of the water column for several minutes during the dawn or dusk periods $(n=4)$. These shallow periods lasted from 39 to $169 \mathrm{~min}$.

\section{Discussion}

We present a first examination of the effect of FAD association on diel movement patterns of dolphinfish. Overall, individuals remained in the uniform-temperature surface layer in congruence with results of other studies on tracking dolphinfish (Furukawa et al., 2011, 2014; Merten et al., 2014 c), as well as with results from studies on tracking wahoo (Acanthocybium solandri; Sepulveda et al., 2011) and sailfish (Chiang et al., 2011). However, we found differences in the vertical movement patterns between FAD-A fish and FAD$\mathrm{U}$ fish. The distributions of the former were extremely shallow, with deeper excursions observed during the day. In contrast, the latter ranged throughout the upper $100 \mathrm{~m}$ of the water column and made deeper descents at night. The differences in behavior of FAD-A and FAD-U fish can 
be noted particularly in the behavior of fish 4 , which became associated partway through the period in which it was actively tracked (Fig. 1). These results are similar to those from studies of bigeye tuna (Thunnus obesus): deeper diving occurred when fish were not associated with surface objects and shallow distribution was generally uniform during day and night when fish were associated with surface objects (Holland et al., 1990b; Musyl et al., 2003).

The difference in depth distribution between FAD-A and FAD-U dolphinfish may be due to differences in feeding strategy. Although Taquet (2004) found that only $27 \%$ of the diet of FAD-A dolphinfish comes from FAD-associated organisms, dolphinfish are primarily visual predators (Massutí et al., 1998) and would be expected to forage primarily during the daytime. For FAD-A fish, deeper daytime dives may represent attempts to forage for prey species distributed throughout the uniform-temperature surface layer. If this is the case, the motivation to make deeper descents would be lessened at night because reduced light levels make foraging difficult.

The broad patterns of vertical movement that we observed in FAD-U dolphinfish are similar to the behaviors observed in other large pelagic fishes, such as tropical tunas and marlin, unassociated with a FAD or debris (e.g., Holland et al., 1990a, 1990b; Brill et al., 1993, Musyl et al., 2003). Such movement patterns may allow fish to explore the water column for prey. During the day, FAD-U dolphinfish may target prey that occupy the uniform-temperature surface layer-prey species that likely are not part of the deep scattering layer. However, at night, dolphinfish may forage on prey of the deep scattering layer that rise to occupy the uniform-temperature surface layer. Although we did not observe the dissociation of any fish from a FAD, Taquet et al. (2007) suggested the need to forage may prompt dolphinfish to leave FADs or other floating objects.

The rapid, deep descents of 4 fish immediately after release were likely a response to tagging because these fish quickly resumed vertical movement patterns that were maintained for extended periods and, therefore, presumably represent natural behavior (Girard et al., 2007). The remaining 8 individuals showed no such initial response. Hoolihan et al. (2011) suggested that stress from capture and handling affects the behavior of large pelagic fishes for periods that span from days to weeks after release. However, a comparison of vertical movement behaviors from our study with those from other acoustic telemetry studies (with tracking conducted for $\sim 24-48 \mathrm{~h}$ after release) and with those from studies that employ im-
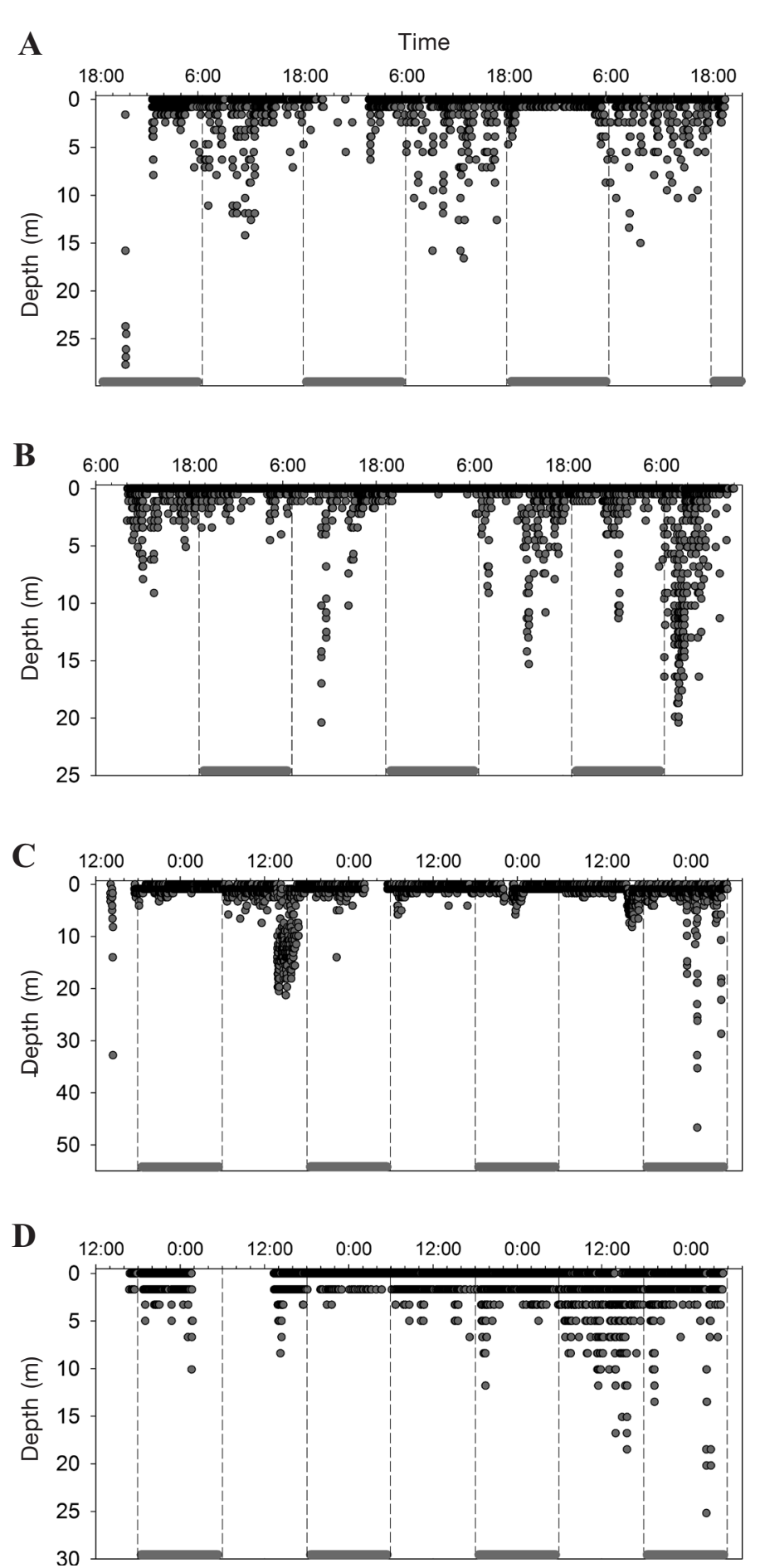

Figure 3

Swimming depths of 4 dolphinfish (Coryphaena hippurus) associated with a fish aggregating device and monitored passively with V13P$1 \mathrm{H}$ or $\mathrm{V} 16-4 \mathrm{H}$ transmitters over periods of several days in the open sea in the southwestern Indian Ocean or near the Seychelles Plateau. (A-C) Fish 9, 11, and 12 were tracked in 2001 and 2004. (D) Fish 10 was tracked in 2003. Individual dots represent detections by the acoustic receiver. Bold gray lines above the $x$-axes indicate nighttime. 
planted archival tags and pop-up satellite archival tags (with tags often containing months long data records) showed remarkable similarity and indicates that 1 ) recovery after release for pelagic teleosts, such as tunas and billfishes, requires only $2-6 \mathrm{~h}$ (Holland et al., 1990a, 1990b; Brill et al., 1993) and 2) differences in vertical movement patterns can be explained largely by differences in oceanographic conditions and prey distributions (e.g., Dewar et al., 2011; Schaefer et al., 2007, 2011).

We observed 2 fish that interrupted their regular patterns of vertical movement during crepuscular periods to remain instead in the upper $10 \mathrm{~m}$ of the water column. These shallow periods may enhance the ability of fish to use sunrise and sunset as zeitgebers to entrain a circadian clock (Aschoff, 1965; Takahashi and Zatz, 1982; Neilson and Perry, 1990) or may represent optimal times for feeding on shallow-water prey, such as flying fish, a main portion of the diet of dolphinfish (Olson and Galván-Magaña, 2002). Merten et al. (2014c) also posited that dawn and dusk were periods of transition that represent the end and start, respectively, to more extensive vertical movements. Bluefin tuna (Thunnus thynnus) have been observed to occasionally interrupt their regular day or night dive behavior at crepuscular periods (Gunn and Block, 2001). However, rather than remaining at shallow depths, these fish make "spike dives" that may have a navigational role through the detection of polarized light patterns or magnetic anomalies (Willis et al., 2009).

The results presented here should be examined further in future studies. Because of resource constraints, our sample size is relatively small and does not encompass different life stages. Although location was determined to be an insignificant factor in our model, there may be differences between populations that were undetectable here. To help determine how vulnerable dolphinfish are to fishing pressure, more work is needed to investigate the original drivers behind FAD association if they are not a source of prey and to determine sexual or life-stage preference for FAD associations. Further studies may incorporate the use of accelerometry (e.g., Furukawa et al., 2011) or further vertical movement profiles from time series data (e.g., Merten et al., 2014c) in order to further elucidate proximate drivers of the difference in behavior between FAD-A and FAD-U fish that was observed in our study.

Our results show that, as with results reported for bigeye tuna (Holland et al., 1990b, Schaefer and Fuller, 2005,2010 ), it may be possible to use information on vertical behavior to assess when an individual dolphinfish is associated with a floating object. Combined with the long-term data-recording capabilities of archival tag studies (Gunn and Block, 2001), information on the impact of FAD association on swimming depth could help elucidate the dependence of dolphinfish on floating objects. This information is key in assessing the effects of fisheries on populations of dolphinfish given the increasing use of FADs by the purse-seine fisheries that target tunas and given the substantial bycatch of dolphinfish (Dagorn et al., 2013, Fonteneau et al., 2013, Leroy et al.,
2013). The findings presented here regarding the vertical distributions of FAD-A and FAD-U dolphinfish may help to develop sustainable fishing techniques and management regulations of FAD-based fisheries.

\section{Acknowledgments}

Tagging in the Indian Ocean was cofunded by the European Union Fish Aggregating Devices as Instrumental Observaties of pelagic ecosystems (FADIO) project (DG Research, QLRI-CT-2002-02773) and the European Union Dynamique et Organisation des Ressources Associées aux Dispositifs Epipélagiques (DORADE) project (DIRED-Ifremer No. 31008/DIRED/JPP/ rp), with additional support from the Regional Council of Reunion Island. We are grateful to the crews of the MV Indian Ocean Explorer and FV Cap Morgan, to the French and Spanish skippers of the purse-seine fishing fleet in the Indian Ocean for their collaboration, and to C. White for analytical advice. C. Girard benefited from a grant provided by the Région Réunion.

\section{Literature cited}

Aschoff, J.

1965. The phase-angle difference in circadian periodic-

ity. In Circadian clocks (J. Aschoff, ed.), p. 262-278. North Holland Press, Amsterdam.

Bates, D., M. Mächler, B. M. Bolker, and S. C. Walker.

2015. Fitting linear mixed-effects models using lme4. J. Stat. Softw. 67(1):1-47. Article

Baughman, J. L.

1941. On a heavy run of dolphin, Coryphaena hippurus, off the Texas coast. Copeia 1941:117. Article

Beardsley, G. L., Jr.

1967. Age, growth and reproduction of dolphin, Coryphaena hippurus, in the Straits of Florida. Copeia 1967:441-451. Article

Boggs, C. H.

1992. Depth, capture time, and hooked longevity of longlinecaught pelagic fish: timing bites of fish with chips. Fish. Bull. 90:642-658.

Brill, R. W., D. B. Holts, R. K. C. Chang, S. Sullivan, H. Dewar, and F. G. Carey.

1993. Vertical and horizontal movements of striped marlin (Tetrapturus audax) near the Hawaiian Islands, determined by ultrasonic telemetry, with simultaneaous measurement of ocean currents. Mar. Biol. 117:567-574. Article

Casazza, T. L., and S. W. Ross.

2008. Fishes associated with pelagic Sargassum and open water lacking Sargassum in the Gulf Stream off North Carolina. Fish. Bull. 106:348-363.

Chiang, W.-C., M. K. Muysl, C.-L. Sun, S.-Y. Chen S. Y., W.-Y. Chen, D.-C. Liu, W.-C. Su, S.-Z. Yeh, S.-C. Fu, and T. L. Huang. 2011. Vertical and horizontal movements of sailfish (Istiophorus platypterus) near Taiwan determined using popup satellite tags. J. Exp. Mar. Biol. Ecol. 387:129-135. Article

Dagorn, L., D. Pincock D., C. Girard, K. Holland, M. Taquet, G. Sancho G., D. Itano, and R. Aumeeruddy.

2007. Satellite-linked acoustic receivers to observe behav- 
ior of fish in remote areas. Aquat. Living Resour. 20:307312. Article

Dagorn, L., K. N. Holland, V. Restrepo, and G. Moreno.

2013. Is it good or bad to fish with FADs? What are the real impacts of the use of drifting FADs on pelagic marine ecosystems? Fish Fish. 14:391-415. Article

Dempster, T., and M. Taquet.

2004. Fish aggregation device (FAD) research: gaps in current knowledge and future directions for ecological studies. Rev. Fish Biol. Fish. 14:21-42. Article

Dewar, H., E. D. Prince, M. K. Muysl, R. W. Brill, C. Sepulveda, J. Luo, D. Foley, E. S. Orbesen, M. L. Domeier, N. Nasby-Lucas, et al.

2011. Movements and behaviors of swordfish in the Atlantic and Pacific Oceans examined using pop-up satellite archival tags. Fish. Oceanogr. 20:219-241. Article

FAO (Food and Agriculture Organization of the United Nations).

2013. Species fact sheets: Coryphaena hippurus (Linnaeus, 1758). FAO, Rome. [Available at website, accessed March 2015.]

Farrell, E. R., A. M. Boustany, P. N. Halpin, and D. L. Hammond. 2014. Dolphinfish (Coryphaena hippurus) distribution in relation to biophysical ocean conditions in the northwest Atlantic. Fish. Res. 151:177-190. Article

Fonteneau, A., E. Chassot, and N. Bodin.

2013. Global spatio-temporal patterns in tropical tuna puse seine fisheries on drifting fish aggregating devices (DFADs): taking a historical perspective to inform current challenges. Aquat. Living Resour. 26:37-48. Article

Furukawa, S., R. Kawabe, S. Ohshimo, K. Fujioka, G. N. Nishihara, Y. Tsuda, T. Aoshima, H. Kanehara H., and H. Nakata. 2011. Vertical movement of dolphinfish Coryphaena hippurus as recorded by acceleration data-loggers in the northern East China Sea. Environ. Biol. Fish. 92:89-99. Article

Furukawa, S., S. Ohshimo, S. Tomoe, T. Shiraishi, N. Nakatsuka, and R. Kawabe.

2012. Age, growth, and reproductive characteristics of dolphinfish Coryphaena hippurus in the waters off west Kyushu, northern East China Sea. Fish. Sci. 78:1153-1162. Article

Furukawa, S., Y. Tsuda, G. N. Nishihara, K. Fujioka, S. Ohshimo, S. Tomoe, N. Nakatsuka, H. Kimura, T. Aoshima, H. Kanehara, et al.

2014. Vertical movements of Pacific bluefin tuna (Thunnus orientalis) and dolphinfish (Coryphaena hippurus) relative to the thermocline in the northern East China Sea. Fish. Res. 149:86-91. Article

Girard, C., L. Dagorn, M. Taquet, R. Aumeeruddy, C. Peignon, and S. Benhamou.

2007. Homing abilities of dolphinfish (Coryphaena hippurus) displaced from fish aggregating devices (FADs) determined using ultrasonic telemetry. Aquat. Living Resour. 20:313-321. Article

Gunn, J. S., and B. Block.

2001. Advances in acoustic, archival, and satellite tagging of tunas. Fish Physiol. 19:167-224. Article

Holland, K., R. Brill, S. Ferguson, R. Chang, and R. Yost.

1985. A small vessel technique for tracking pelagic fish. Mar. Fish. Rev. 47:26-32.

Holland, K. N., R. W. Brill, and R. K. C. Chang.

1990a. Horizontal and vertical movements of Pacific blue marlin captured and released using sportfishing gear. Fish. Bull. 88:397-402. 1990b. Horizontal and vertical movements of yellowfin and bigeye tuna associated with fish aggregation devices. Fish. Bull. 88:493-507.

Hoolihan, J. P.

2005. Horizontal and vertical movements of sailfish (Istiophorus platypterus) in the Arabian Gulf, determined by ultrasonic and pop-up satellite tagging. Mar. Biol. 146:1015-1029. Article

Hoolihan, J. P., J. Luo, F. J. Abascal, S. E. Campana, G. De Metrio, H. Dewar, M. L. Domeier, L. A. Howey, M. E. Lutcavage, M. K. Musyl et al.

2011. Evaluating post-release behaviour modification in large pelagic fish deployed with pop-up satellite archival tags. ICES J. Mar. Sci. 68:880-889. Article

Leroy, B., J. S. Phillips, S. Nicol, G. M. Pilling, S. Harley, D. Bromhead, S. Hoyle, S. Caillot, V. Allain, and J. Hampton.

2013. A critique of the ecosystem impacts of drifting and anchored FADs use by purse-seine tuna fisheries in the western and central Pacific Ocean. Aquat. Living Resour. 26:49-61. Article

Massuti, E., Deudero S., Sanchez P., and Morales-Nin B.

1998. Diet and feeding of dolphin (Coryphaena hippurus) in western Mediterranean waters. Bull. Mar. Sci. 63:329-341.

Merten, W., R. Appeldoorn, and D. Hammond.

2014a. Movements of dolphinfish (Coryphaena hippurus) along the U.S. East Coast as determined through mark and recapture data. Fish. Res. 151:114. Article

2014b. Spatial differentiation of dolphinfish (Coryphaena hippurus) movements relative to the Bahamian archipelago. Bull. Mar. Sci. 90:849-864.

Merten, W., R. Appeldoorn, R. Rivera, and D. Hammond.

2014c. Diel vertical movements of adult male dolphinfish (Coryphaena hippurus) in the western central Atlantic as determined by use of pop-up satellite archival transmitters. Mar. Biol. 161:1823-1834. Article

Musyl, M. K., R. W. Brill, C. H. Boggs, D. S. Curran, T. K. Kazama, and M. P. Seki.

2003. Vertical movements of bigeye tuna (Thunnus obesus) associated with islands, buoys, and seamounts near the main Hawaiian Islandsfrom archival tagging data. Fish. Oceanogr. 12:152-169. Article

Neilson, J. D., and R. I. Perry.

1990. Diel vertical migrations of marine fishes: an obligate or facultative process? In Advances in marine biology, vol. 26 (J. H. Blaxter and A. J. Southward, eds.), p. 115168. Academic Press, San Diego.

Norton, J. G.

1999. Apparent habitat extensions of dolphinfish (Coryphaena hippurus) in response to climate transients in the California current. Sci. Mar. 63:239-260. Article

Olson, R. J., and F. Galván-Magaña.

2002. Food habits and consumption rates of common dolphinfish (Coryphaena hippurus) in the eastern Pacific Ocean. Fish. Bull. 100:279-298.

Oxenford, H. A.

1999. Biology of the dolphinfish (Coryphaena hippurus) in the western central Atlantic: a review. Sci. Mar. 63:277-301. Article

Oxenford, H. A., and W. Hunte.

1999. Feeding habits of the dolphinfish (Coryphaena hippurus) in the eastern Caribbean. Sci. Mar. 63:303315. Article

Palko, B. J., G. L. Beardsley, and W. J. Richards. 1982. Synopsis of the biological data on dolphin-fishes, 
Coryphaena hippurus Linnaeus and Coryphaena equiselis Linnaeus. FAO Fish. Synop. 130. NOAA Tech. Rep. NMFS Circ. 443, 28 p.

Rodríguez-Ferrer, G., Y. Rodríguez-Ferrer, D. Matos-Caraballo, and C. L. Yestrom.

2004. Comparison of dolphinfish (Coryphaena hippurus) commercial and recreational fisheries in Puerto Rico during 2000-2003. Proc. Gulf Caribb. Fish. Inst. 57:297-316.

$\mathrm{R}$ Core Team.

2013. R: a language and environment for statistical computing. R Foundation for Statistical Computing, Vienna, Austria. [Available from website, accessed March 2015.]

Rooker, J. R., J. P. Turner, and S. A. Holt.

2006. Trophic ecology of Sargassum-associated fishes in the Gulf of Mexico determined from stable isotopes and fatty acids. Mar. Ecol. Prog. Ser. 313:249-259. Article

Rose, C. D., and W. W. Hassler.

1974. Food habits and sex ratios of dolphin Coryphaena hippurus captured in the western Atlantic Ocean off Hatteras, North Carolina. Trans. Am. Fish. Soc. 103:94-100. Article

Rudershausen, P. J., J. A. Buckel, J. Edwards J., D. P. Gannon, C. M. Butler, and T. W. Averett.

2010. Feeding ecology of blue marlins, dolphinfish, yellowfin tuna, and wahoos from the North Atlantic Ocean and comparisons with other oceans. Trans. Am. Fish. Soc. 139:1335-1359. Article

Schaefer, K. M., and D. W. Fuller.

2005. Behavior of bigeye (Thunnus obesus) and skipjack (Katsuwonus pelamis) tunas within aggregations associated with floating objects in the equatorial eastern Pacific. Mar. Biol. 146:781-792. Article

2010. Vertical movements, behavior, and habitat of bigeye tuna (Thunnus obesus) in the equatorial eastern Pacific Ocean, ascertained from archival tag data. Mar. Biol. 157:2625-2642. Article

Schaefer, K. M., D. W. Fuller, and B. A. Block.

2007. Movements, behavior, and habitat utilization of yellowfin tunas (Thunnus albacares) in the northeastern Pacific Ocean, ascertained through archival tag data. Mar. Biol. 152:503-525. Article

2011. Movements, behavior, and habitat utilization of yellowfin tunas (Thunnus albacares) in the Pacific Ocean off Baja California, Mexico, determined from archival tag data analysis, including unscented Kalman filtering. Fish. Res. 112:22-37. Article

Schwenke, K. L., and J. A. Buckel.

2008. Age, growth, and reproduction of dolphinfish (Coryphaena hippurus) caught off the coast of North Carolina. Fish. Bull. 106:82-92.

Sepulveda, C. A., S. A. Aalbers, S. Ortega-Garcia, N. C. Wegner, and D. Bernal.

2011. Depth distribution and temperature preferences of wahoo (Acanthocybium solandri) off Baja California Sur, Mexico. Mar. Biol. 158:917-926. Article

Takahashi, J. S., and M. Zatz.

1982. Reculation of circadian rhythmicity. Science 217: 1104-1111. Article

Taquet, $\mathrm{M}$.

2004. Le comportement agrégatif de la dorade coryphène (Coryphaena hippurus) autour des objets flottants. Ph.D. thesis, 168 p. Univ. Paris, Paris.

Taquet, M., G. Sancho, L. Dagorn, J.-C. Gaertner, D. Itano, R. Aumeeruddy, B. Wendling, and C. Peignon.

2007. Characterizing fish communities associated with drifting fish aggregating devices (FADs) in the Western Indian Ocean using underwater visual surveys. Aquat. Living Resour. 20:331-341. Article

Tremblay, A., and J. Ransijn.

2013. LMERConvenienceFunctions: a suite of functions to back-fit sized effects and forward-fit random effects, as well as other miscellaneaous functions. $\mathrm{R}$ package, vers. 2.5 .

Tripp-Valdez, A., F. Galván-Magaña F., and S. Ortega-García. 2010. Feeding habits of dolphinfish (Coryphaena hippurus) in the southeastern Gulf of California, Mexico. J. Appl. Ichthyol. 26:578-582. Article

Trippel, E. A.

1995. Age at maturity as a stress indicator in fisheries. BioScience 45:759-771. Article

Willis, J., J. Phillips, R. Muheim, F. J. Diego-Rasilla, and A. J. Hobday.

2009. Spike dives of juvenile southern bluefin tuna (Thunnus maccoyii): a navigational role? Behav. Ecol. Sociobiol. 64:57-68. Article 